\title{
TENDÊNCIAS METODOLÓGICAS DA PESQUISA EM ENSINO DE QUÍMICA NA REVISTA “QUÍMICA NOVA NA ESCOLA” - 1995 A 2017
}

\section{METHODOLOGICAL TRENDS IN CHEMISTRY TEACHING RESEARCH IN THE JOURNAL “QUÍMICA NOVA NA ESCOLA” - 1995 TO 2017}

\author{
Flávia Caroline Bedin ${ }^{1}$ \\ Franciellen Rodrigues da Silva Costa ${ }^{2}$ \\ Alvaro Lorencini Júnior ${ }^{3}$ \\ Neide Maria Michellan Kiouranis ${ }^{4}$
}

\begin{abstract}
Resumo: Com o crescimento do Ensino de Química como área de conhecimento, cresce também a difusão dos trabalhos de pesquisa nela realizados. Uma vez que esse campo vem se consolidando, é importante compreendermos quais as tendências metodológicas têm sido empregadas. Para tanto, buscou-se investigar as publicações da seção "Pesquisa no Ensino de Química/Química em Foco" da revista Química Nova na Escola (QNEsc). Após a análise, observou-se que as pesquisas têm se caracterizado quanto ao caráter qualitativo, com a predominância do "estudo de caso". Acredita-se que mesmo avançando quanto às questões metodológicas, ainda existem lacunas que precisam ser preenchidas para que as pesquisas sejam fortalecidas e ganhem cada vez mais espaço significativo no cenário científico.
\end{abstract}

Palavras-chave: QNEsc; Educação Química; Tendências Metodológicas.

\begin{abstract}
With the growth of Teaching of Chemistry as an area of knowledge, it is also growing the diffusion of the research works carried out in this area. Once this field has been consolidated, it is important to understand what methodological trends have been employed. Therefore, we sought to investigate the publications of the section "Research in Teaching of Chemistry/Chemistry in Focus" of the journal Química Nova na Escola (QNEsc). After the analysis, we observe that the research has been characterized as to the qualitative character, with the predominance of the "case study". We believe that even advancing on the methodological issues, there are still gaps that need to be filled for research to be strengthened and gain more and more significant space in the scientific scenario.
\end{abstract}

Keywords: QNEsc; Chemical Education; Methodological Trends.

\section{Introdução}

O Ensino de Química é uma área de conhecimento que vem se desenvolvendo e se consolidando nos últimos 40 anos. Segundo Schnetzler (2002), o campo da pesquisa caracteriza-se como uma nova área de investigação "marcada pela especificidade do

\footnotetext{
${ }^{1}$ Mestre em Química, Universidade Tecnológica Federal do Paraná (UTFPR). Universidade Estadual de Maringá (UEM), Maringá, Paraná, Brasil. E-mail: flaviabedin@ gmail.com

${ }^{2}$ Mestre em Educação em Ciências, Universidade Federal do Paraná (UFPR). Universidade Estadual de Maringá (UEM), Maringá, Paraná, Brasil. E-mail: franciellencostaa@ gmail.com

3 Doutor em Educação em Ciências, Faculdade de Educação da Universidade de São Paulo (USP). Universidade Estadual de Londrina (UEL), Londrina, Paraná, Brasil. E-mail: lorencinijunior@gmail.com

${ }^{4}$ Doutora em Educação em Ciências, Universidade Estadual Paulista (UNESP). Universidade Estadual de Maringá (UEM), Maringá, Paraná, Brasil. E-mail: nmmkiouranis@ gmail.com
} 
conhecimento químico, que está na raiz dos problemas de ensino e de aprendizagem investigados" (SCHNETZLER, 2002, p.15). As pesquisas em Ensino de Química têm como um dos propósitos investigar os processos que dão conta de uma melhor reelaboração de conhecimentos químicos em domínios escolar, na compreensão do sobre "o que”, "como" e "por quê" ensinar Química. Em um outro artigo, Schnetzler e Aragão (1995) afirmam que o maior reconhecimento dessa área está em sua capacidade de solucionar problemas que as outras áreas da química não são capazes de explicar, uma vez que o conhecimento químico é apenas uma das condições necessárias para a resolução, mas não a única para um bom processo de ensino e de aprendizagem. A mesma utiliza das contribuições de áreas como a Filosofia, Sociologia, Psicologia, entre outras; indo contra a ideia de que para ser professor, basta apenas a apropriação do conhecimento específico das áreas para solucionarmos os problemas que envolvem a sala de aula.

Um dos fatores apontados por Schnetzler (2002) como grande marco no desenvolvimento das pesquisas em Ensino de Química, foi a criação da revista Química Nova na Escola (QNEsc). As publicações na revista "Química Nova na Escola" têm corroborado para a construção e consolidação do Ensino de Química como área de pesquisa. Com a dimensão de alcançar muitos professores para apropriar-se das propostas publicadas e trazê-las para seu espaço e contexto escolar, estimulando a mudança e promovendo discussões acerca de novas ações. Além disso, possibilita um espaço de compartilhamento de informações e conhecimentos que alcançam todos os níveis de ensino e insere os futuros professores nas discussões atuais e pertinentes de sua formação.

O crescimento e difusão das publicações na área de Ensino de Química contou com os resultados provenientes dos novos programas de pós-graduação no Brasil. Isso corroborou também para fundamentar o conhecimento entre os pesquisadores dos diferentes tipos de pesquisa, a variedade de instrumentos de coleta de dados, bem como as metodologias de análises dessas informações (CAPES, 2017).

Esta área, segundo Mól (2017), ao contrário das áreas tradicionais da Química (Analítica, Físico, Química, Inorgânica), migrou das pesquisas quantitativas para qualitativas e, com isso, surgiu a necessidade de se considerar a cultura e as interações sociais. Logo, existe a preocupação de olhar para essas pesquisas qualitativas, frutos deste novo campo de pesquisa, em busca averiguar o seu rigor científico determinado por seus paradigmas metodológicos. Sendo assim, a ausência de definição das metodologias empregadas na pesquisa qualitativa pode inviabilizar uma primeira avaliação dos trabalhos no que diz respeito à sua relação com o objeto de estudo e instrumentos adotados 
(SANTOS; GRECA, 2013).

Em torno desta inquietação que remete a falta de compreensão sobre os procedimentos metodológicos utilizados na(s) pesquisa(s), especificamente na área de Ensino de Química, buscou-se investigar quais as tendências metodológicas têm sido empregadas nos estudos dedicados a área de Ensino de Química, publicadas em forma de artigos na Revista Química Nova na Escola (QNEsc), desde o ano de sua implementação, 1995, até o ano de 2017.

\section{Embasamento Teórico}

\subsection{O Ensino de Química no Brasil}

Segundo Schnetzler (2002), o Ensino de Química como área de pesquisa, em nosso país, se consolidou devido a seis grandes marcos. Dentre eles, se pode citar a constituição da área de Ensino na Sociedade Brasileira de Química, a consolidação de importantes eventos de divulgação científica, como os Encontros Nacionais e Regionais de Ensino de Química e a criação da revista Química Nova na Escola. Além do surgimento dos programas de pós-graduações em Educação em Ciências e Matemática, distribuídos pelo país (NARDI, 2015).

A área de Ensino de Química caracteriza-se como um subcampo da Educação em Ciências e Matemática. Esse campo foi institucionalizado pela Coordenação de Aperfeiçoamento de Pessoal de Nível Superior (CAPES) como Área de Ensino de Ciências e Matemática (Área 46) no ano 2000. A evolução e expansão significativa da área refletiu na criação de vários programas de pós-graduação e cursos de licenciatura, conforme o relatório de avaliação trienal da CAPES (2009). Em 2011, devido a mudanças no que tange à estrutura no âmbito da CAPES, esse campo de estudo migrou e passou a integrar à uma das quatro novas grandes áreas criadas com a instituição da portaria CAPES 83/2011, a Área de Ensino. Conforme o relatório de avaliação divulgado pela CAPES, referente ao quadriênio de 2013-2016, a área de Ensino se consolidou tanto em termos qualitativos quanto quantitativos, passando de 104 para 157 programas de pósgraduações ativos, num total de 177 cursos (CAPES, 2017).

O crescimento da área também foi investigado por pesquisadoras como Francisco e Queiroz (2015). As pesquisadoras realizaram um estudo da produção acadêmica brasileira sobre o Ensino de Química em programas de pós-graduação em Ensino de Ciências e Matemática, analisando 152 dissertações e duas teses de doutorado defendidas 
sobre este campo de estudo, entre 2000 e 2008. Entre as observações, as autoras apontaram que a superioridade do número de dissertações em relação às teses na época indica o quão recente encontra-se a área de pesquisa. Porém, o crescente número de trabalhos publicados, indicam a disseminação efetiva da área ao longo dos anos.

Com a expansão, surgiram também novas tendências metodológicas junto aos programas de pós-graduação de forma a expressar os paradigmas vigentes. Entretanto, segundo Scarpa e Marandino (1999), questões metodológicas e referentes às abordagens de pesquisa não têm sido tão enfocadas pelos pesquisadores no Ensino de Ciências. As autoras afirmam que com o amadurecimento da área é importante se refletir sobre o que tem sido feito quanto às abordagens metodológicas, ressaltando a necessidade de aprofundar o conceito de pesquisa qualitativa, a fim de evitar apropriações inadequadas ou mesmo a falta de explicitação dos processos metodológicos inerentes às mesmas. Isso auxiliará para uma visão mais contextualizada da produção científica, possibilitando assim, um aprofundamento maior sobre o tema no sentido de identificar as lacunas existentes e indicar possíveis caminhos para soluções necessárias.

\subsection{Pesquisa no Ensino de Química}

Falar das metodologias para a pesquisa no Ensino de Química, necessita-se refletir acerca de uma definição dos paradigmas atribuídos para a investigação. Nesse caso, Coutinho (2014, p. 9) define o conceito de paradigma como "um conjunto articulado de postulados, de valores conhecidos, de teorias comuns e de regras que são aceitas por todos os elementos de uma comunidade científica num dado momento histórico".

Com isso, os paradigmas de investigação têm o papel de cumprir duas funções principais: unificação de conceitos, de cunho teórico e metodológico e, a outra função, de legitimação entre os investigadores, relacionados aos critérios de validade e interpretação (COUTINHO, 2014).

Atualmente, no que diz respeito à pesquisa em Ensino de Química, existem dois paradigmas em destaque: o qualitativo e o quantitativo. De modo geral, segundo a autora supracitada, o paradigma qualitativo utiliza métodos de análise capazes de interpretar as mais diversas interações subjetivas dentro da pesquisa, investigando as relações e interações sociais de maneira menos generalizada (método indutivo). Ressaltando que as teorias são construídas depois do processo de análise de resultados, levando em consideração todas as interações sociais e individuais dos sujeitos existentes no processo. 
Já o paradigma quantitativo, possui um princípio de pesquisa mais linear e generalizante, apresenta maior ênfase nos fatos e desconsidera as variáveis subjetivas. Sua investigação tem como norte a teoria, possui questões mais objetivas de estudo e faz uso de ferramentas estatísticas para análise de dados.

A partir da delimitação do paradigma para investigação é necessário repensar na caracterização dessas pesquisas devido suas especificidades. Segundo Flick (2004), existe uma variedade enorme de métodos disponíveis, partindo das mais diversas premissas possíveis, mas o que vai determinar a utilização desses é o objetivo de pesquisa.

No caso da pesquisa qualitativa, pesquisadores da área (COUTINHO, 2014; GIL, 2002; CHIZZOTTI, 2016) têm apontado diferentes métodos. Entre eles estão: a pesquisa etnográfica, estudo de caso, pesquisa-ação, pesquisa bibliográfica, pesquisa participante, pesquisa documental, história de vida, entre outras. Já na pesquisa quantitativa, destacase o método experimental.

Segundo Mól (2017, p. 502) “os padrões metodológicos de uma disciplina são definidos a partir de padrões de outras disciplinas, por meio de apropriações do que se avalia como relevante e significativo". Nas pesquisas da área do Ensino de Química seus métodos derivam de procedimentos das Ciências Humanas e, também, possuem forte vínculo com os aspectos das Ciências Exatas. Porém, ao se falar da Educação, seus objetos não podem ser reduzidos a simples variáveis, precisam ser considerados de forma holística e sua validade precisa ser testada por materiais empíricos, pelo posicionamento do pesquisador, seus referenciais teóricos, pela descrição detalhada dos métodos, a validade dos procedimentos, entre outros (MÓL, 2017).

Um ponto muito importante para o desenvolvimento da pesquisa é o recolhimento dos dados, sejam esses de caráter qualitativo ou quantitativo. Independente do caráter da pesquisa, é indispensável assegurar a validade e a fidedignidade dos dados recolhidos durante o processo, conferindo assim, uma maior qualidade à investigação.

Essa questão da fidedignidade também se aplica às metodologias de análise dos dados obtidos. Há uma variedade de técnicas de análise disponíveis, bem como das diferentes formas de se analisar as informações recolhidas, a opção por uma delas ficará a cargo do investigador e de seu objeto de pesquisa. Dentre as metodologias de análise qualitativas, podem ser citadas, a análise de conteúdo, análise de discurso, análise textual discursiva, análise de narrativas, dentre outras.

Segundo Santos e Greca (2013), em um estudo sobre as metodologias de pesquisa no ensino de Ciências na América Latina na década de 2000, boa parte do embasamento 
metodológico nessa área fica restrita a pequenos cursos durante a pós-graduação, o que mostra a tendência na utilização dos métodos e técnicas tradicionalmente adotados pelo grupo de pesquisa no qual o investigador se insere. Com isso, as autoras apontam a necessidade de se investir mais tempo na formação metodológica, a fim de melhorar a qualidade da pesquisa no Ensino de Ciências. Outro aspecto levantado pelas autoras, é que a pesquisa na área da educação é muito complexa para ser abordada apenas pelo paradigma qualitativo e que a pesquisa na área das ciências perde muito por se restringir a apenas um ponto de vista, uma vez que essas perspectivas, qualitativas e quantitativas, estão intimamente imbricadas e permitem mapear aspectos diferentes da realidade educativa.

O trabalho realizado por Mortimer e colaboradores (2015), analisou os artigos da revista QNEsc no período de 2005 a 2014, fazendo um breve comparativo com a primeira década de publicação da mesma. O que os autores afirmam é que a seção de Pesquisa no Ensino, passou de penúltima para segunda colocada em termos de quantidade de publicações, o que indica a expansão da área e crescimento de pesquisadores interessados em desenvolver pesquisas no campo. Os autores também apontam que a maioria dos trabalhos se enquadram ao rigor científico das pesquisas, pela presença de uma questão de investigação, norteada pelo uso de um referencial teórico consistente, pela indicação de instrumentos e metodologia para realizar e analisar os dados, apresentando resultados e conclusões relevantes à área.

A partir dessas informações levantadas buscou-se compreender a forma que essa comunidade científica do Ensino de Química, ao longo das publicações na revista QNEsc, vem se consolidando metodologicamente em relação as escolhas dos métodos e das técnicas de investigação adotados pelos pesquisadores.

\section{Procedimentos Metodológicos}

O trabalho aqui descrito é de natureza qualitativa, classificado como pesquisa bibliográfica, cujo objetivo é identificar os instrumentos, as técnicas e as metodologias de análise utilizadas nas pesquisas na área de Ensino de Química dos trabalhos publicados por um periódico da área, a fim de compreender como esse campo de estudo tem se configurado em relação as tendências metodológicas. A pesquisa bibliográfica desenvolvida baseou-se na investigação de materiais já tratados qualitativamente, como é o caso dos artigos científicos. Uma das vantagens dessa pesquisa é fornecer ao 
investigador uma maior amplitude de fenômenos, principalmente, quando o problema requer dados muito dispersos pelo espaço (GIL, 2002).

Dessa forma, as fontes utilizadas para análise de dados foram as publicações da Revista Química Nova na Escola (QNEsc) no período de 1995-2017, disponíveis no próprio site do periódico. Adotou-se essa fonte de recolha de dados devido à importância desse meio de comunicação para a comunidade acadêmica do Ensino de Química, uma vez que nessa revista são divulgadas importantes ações desenvolvidas em parceria entre os pesquisadores da área de Química Analítica, Físico-química, Orgânica, e Inorgânica com os pesquisadores da área de Ensino de Química. Além disso, são divulgadas pesquisas com o foco na formação inicial e continuada dos professores, também pensando nos formadores, uma vez que se discutem os problemas dos cursos de licenciatura em química, a fim de propor melhorias para ensino, bem como apresentar as tendências internacionais e, principalmente, a partir das produções de novos conhecimentos (SCHNETZLER, 2002).

A fim de compreender as tendências metodológicas empregadas nas publicações na área ao longo dos anos, não houve um recorte temporal, compreendendo assim, todos os periódicos publicados desde o lançamento da revista em 1995. Selecionou-se apenas uma das seções temáticas intitulada "Pesquisa no Ensino de Química", a qual, no ano de 2014, passou a ser chamada de "Ensino de Química em Foco". A mudança nominal não alterou as características da seção ${ }^{5}$. A seleção dessa seção como objeto de investigação deve-se aos critérios para submissão de trabalhos, que enfatizam "investigações sobre problemas no Ensino da Química, explicitando os fundamentos teóricos, o problema, as questões ou hipóteses de investigação e procedimentos metodológicos adotados na pesquisa, bem como analisando criticamente seus resultados (QUADROS, 2017, p.5 )”.

Como o objetivo é analisar as tendências metodológicas, dedicou-se a leitura das metodologias dos trabalhos encontrados na seção temática, com o intuito de extrair as informações desejadas. Para esta análise, utilizou-se a metodologia de análise de conteúdo (BARDIN, 2010), que se iniciou pela leitura flutuante dos materiais, seguindo da exploração dos textos para a sua unitarização em unidades de significados a fim de associá-las as seguintes dimensões definidas a priori. Essas dimensões foram fundamentadas pelos referenciais teóricos (COUTINHO, 2014; GIL, 2002; CHIZZOTTI, 2016) e descritas abaixo:

\footnotetext{
${ }^{5}$ Não foi encontrada uma justificativa para a mudança de nomenclatura da seção. Texto extraído do site da Revista - Normas para Submissão.
} 
- Paradigma norteador: este item busca compreender o caráter da pesquisa (qualitativo, quantitativo ou misto);

- Formas de abordagem: classificação segundo os autores conforme o delineamento da pesquisa, podendo ser classificadas como revisão bibliográfica, estudo de caso, pesquisa-ação, dentre outras;

- Instrumento de Recolha de Dados: instrumentos utilizados para recolher as informações da pesquisa;

- Procedimento de Análise de Dados: Quais são as escolhas metodológicas e os referenciais de análise empregados pelos autores para interpretação, discussão e análise dos dados recolhidos, com base nos instrumentos adotados, podendo ser classificadas como Análise do Discurso, Análise do Conteúdo, dentre outras;

A partir destas dimensões de análise foi possível criar um banco de dados com as informações extraídas, para que assim pudéssemos analisar cada item individualmente e, posteriormente, fazer as relações e associações para traçar um perfil metodológico das tendências com base nas informações extraídas. No caso dos trabalhos que não apresentaram estas informações explícitas, atribuiu-se a opção "não consta".

\section{Resultados e Discussões}

Como o intuito da presente investigação foi identificar as tendências metodológicas da pesquisa no Ensino de Química, optou-se por analisar apenas a seção da revista QNEsc em que os artigos publicados apresentam como proposta central divulgar resultados de pesquisas. Nesta seção temática, intitulada "Pesquisa no Ensino de Química/Química em Foco", foram encontrados 86 artigos, descritos de forma cronológica pela sua primeira edição (v.1, n.1 01) em 1995 até a última publicação investigada (v. 37, n.3) em 2017. Ao fazer este levantamento dos artigos publicados na seção neste período, notou-se que, assim como observado por Mortimer e colaboradores (2015), houve um aumento das publicações com o passar dos anos, conforme o Gráfico 1. 
Gráfico 1: Quantidade de publicações na seção de Ensino de Química em Foco por ano

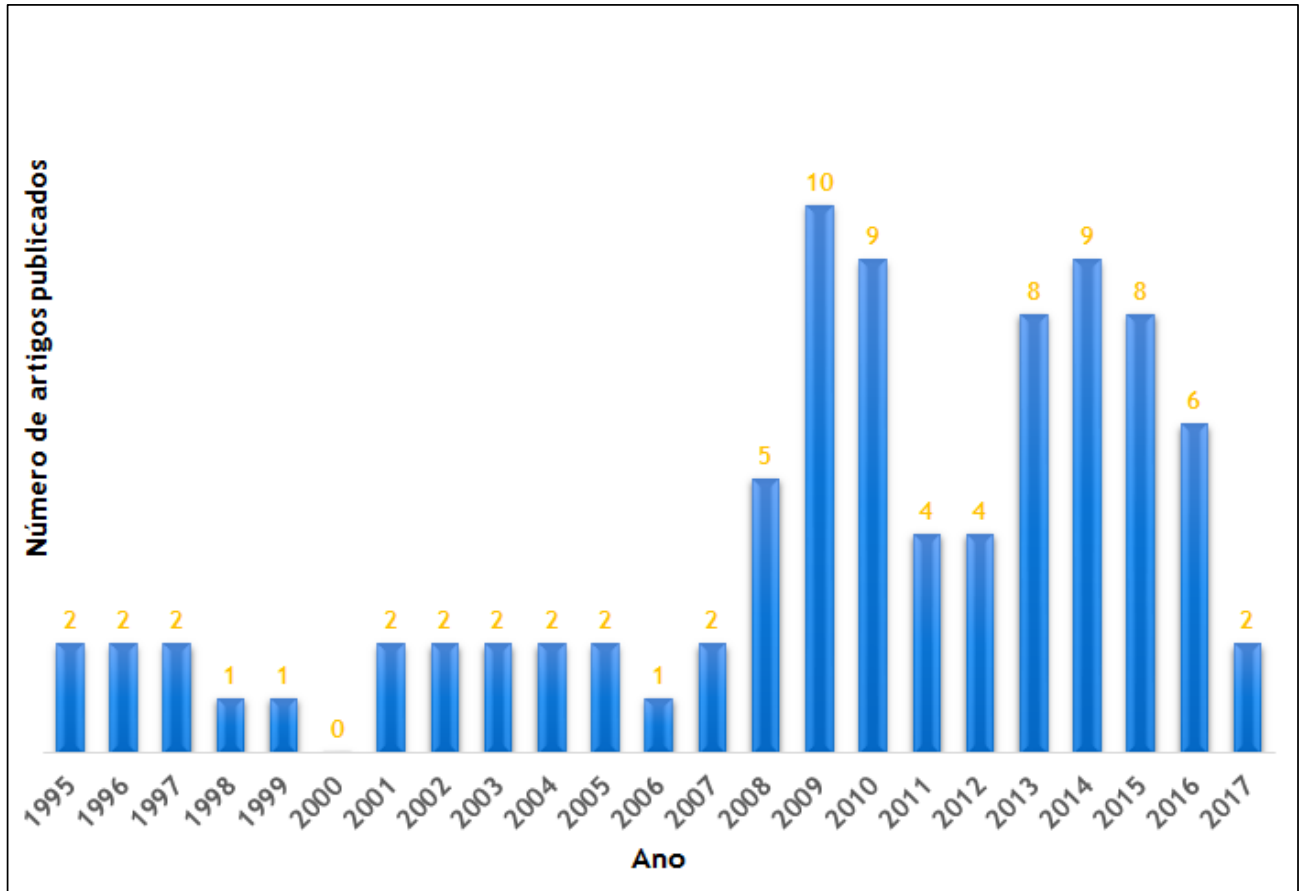

Fonte: Os autores

Esse crescimento significativo na última década, provavelmente, se deve à criação de novos cursos de pós-graduação na área de Ensino de Química/Ensino de Ciências e, consequentemente, a publicação dos resultados das teses e dissertações, como afirmam pesquisadores como: Francisco e Queiroz (2015), Nardi (2015).

Um outro fator que possivelmente pode ter impulsionado as publicações da revista dentro da seção temática, a partir do ano de 2012, são as publicações nas revistas referentes ao Programa Institucional de Bolsas de Iniciação à Docência (PIBID). O que possibilitou a divulgação dos trabalhos de natureza investigativa, realizados por esse projeto no ambiente escolar.

Segundo Santos e Greca (2013), o aumento significativo das publicações no Ensino de Ciências, análogo ao Ensino de Química, fomentou uma pergunta referente à qualidade das pesquisas produzidas, questionando os padrões de validade e fidedignidade da pesquisa qualitativa. Para as autoras, boa parte dos pesquisadores da América Latina não parecem estar preocupados com essas questões, uma vez que estas informações não estão expressas de forma explícita em seus trabalhos e sua ausência enfraquece os resultados obtidos. Considerando que a metodologia empregada se constitui um dos elementos fundamentais, faz-se necessário conhecer as tendências metodológicas mais utilizadas na área, para que assim, tenha-se suporte para investir em desenhos metodológicos mais sofisticados, aumentando a fidedignidade e validade das pesquisas. 


\subsection{Paradigma Norteador}

Nesta primeira dimensão de análise, buscou-se compreender qual é o paradigma prevalecente nas publicações do periódico. Isso devido ao fator já mencionado de que esta área, Ensino de Química, migrou da pesquisa quantitativa para a qualitativa. Sendo assim, torna-se necessário compreender como esta forma de pesquisar tem ganhado espaço nessa área e, além disso, verificar os traços de pesquisas de caráter quantitativo e misto. Enfatizando que um paradigma não é mais importante do que o outro, ou seja, "não existem métodos universais de pesquisa. $\mathrm{O}$ que existem são métodos que melhor se adequam a alguns tipos de problemas e contextos e não a outros (MEDEIROS, 2002, p.67)".

A análise dos dados contidos nos artigos nos mostra que a maioria dos autores, 61 dos 86 trabalhos analisados (71\%), não indicam, explicitamente, o paradigma metodológico adotado dentro de um referencial que justifica seu emprego. Seja esse de caráter qualitativo, quantitativo ou misto. $\mathrm{O}$ que vem ao encontro com os dados encontrados por Scarpa e Marandino (1999), ao analisarem os artigos do Encontro de Pesquisa em Ensino de Ciências (ENPEC), também perceberam problemas de articulação entre os fundamentos epistemológicos e questões metodológicas nos trabalhos publicados.

Como já informado, não foram buscadas outras formas de identificação dos aspectos das pesquisas analisadas. Por mais que de forma implícita, pelo delineamento da pesquisa, pudéssemos enquadrá-la em um paradigma ou outro, o foco deste trabalho foi identificar as informações explícitas citadas pelo autor (es) dos trabalhos. Além disso, conforme apontado por Santos e Greca (2013), nos trabalhos qualitativos muitos procedimentos são quase idênticos, mas sua utilização em relação à teoria e sua finalidade fazem com que sejam tratados de forma diferente. É de extrema importância que a linguagem e os aspectos norteadores do processo de pesquisa estejam claros e evidenciados no trabalho.

Em relação aos que classificaram sua pesquisa dentro de um paradigma de forma explícita, 25 dos 86 trabalhos (correspondendo a 29\% dos trabalhos analisados), quase que em sua totalidade (28\%) definiram-na dentro do paradigma qualitativo. Entre esses, pode-se citar os trabalhos de Benite, Benite e Echeverría (2010) e Souza, Campos e Benite (2014). Em ambos a definição da investigação está explícita e justificada no corpo do texto, como observado no excerto a seguir: "Esta é uma investigação qualitativa, pois 
utiliza técnicas interpretativas para traduzir e expressar o sentido de fenômenos do mundo social (SOUZA; CAMPOS; BENITE, 2014, p. 151)".

A definição das pesquisas como qualitativa começa a aparecer com maior frequência na metodologia dos artigos próximos ao ano de 2008, o que pode ser efeito da implementação dos cursos de pós-graduação e resultados de seus trabalhos. Pode-se observar esse movimento no excerto do trabalho de Mesquita e Soares (2009), em que os utilizam a seguinte definição: Segundo Bogdan e Biklen (1994), "a pesquisa qualitativa envolve a compreensão do processo mediante o qual as pessoas constroem significados, descrevendo em que consistem esses mesmos significados (p. 126).”

No trabalho de Maia et al. (2011) é possível observar esse mesmo movimento de caracterização. Os autores apontam que sua pesquisa "[...] é qualitativa, uma vez que condiz com a definição de Bogdan e Biklen (1994, p. 11), que a entendem como “[...] uma metodologia de investigação que enfatiza a descrição, a indução, a teoria fundamentada e o estudo das percepções pessoais" (p. 117)"

Porém, também se encontrou autores que ao definir sua pesquisa como qualitativa, utilizaram definições empíricas, justificada pela premissa da utilização de recursos na pesquisa para a coleta de dados como a fala e a escrita para tal definição. Como é o caso do trabalho de Melo e Neto (2013), em que os autores justificam a classificação de sua pesquisa a partir do uso dos materiais coletado. "Nossa pesquisa seguiu uma abordagem predominantemente qualitativa, pois nossos dados foram obtidos a partir tanto da fala dos licenciandos como da escrita dos alunos de ensino médio [...] (p. 116)”. Em nenhum dos artigos encontrou-se uma investigação classificada apenas como quantitativa.

Do restante dos trabalhos que classificam suas pesquisas dentro de um paradigma (1\%) definiu-a como pesquisa mista. Os artigos que de fato trouxeram, em nossa perspectiva, uma abordagem mista, foram os artigos de autores estrangeiros, uma vez que estes adotam instrumentos de recolha de dados e de análise embasados nos dois paradigmas, qualitativo e quantitativo. Isto nos aponta que ainda não há consenso para nós, brasileiros, sobre o delineamento metodológico da pesquisa mista dentro da Educação Química, em nosso país. Como por exemplo, o trabalho de Wartha e FaljoniAlário (2005) em que os autores apontam que sua pesquisa, em um segundo momento, "[...] foi realizada a análise dos termos cruzando-se dados quantitativos com dados qualitativos, de modo a otimizar uma maior variação possível entre as categorias (p. 45)". As pesquisas que propuseram a classificação "mista" não apresentaram nenhuma definição teórica para essa metodologia. 
Ferreira (2015), ao discutir sobre as perspectivas da pesquisa qualitativa e quantitativa na área da educação, argumenta que cabe ao pesquisador escolher por uma ou outra abordagem teórico-metodológica pensando em qual poderá trazer maiores contribuições para se alcançar os resultados pretendidos e que a combinação destas metodologias pode favorecer e enriquecer a investigação e análise do objeto de estudo.

Além disso, conforme apontado por Gatti (2004), os métodos de análise de dados que são traduzidos em números podem ser úteis em diversos problemas na área da educação. Mais ainda, a combinação desses dados com os provenientes das metodologias qualitativas, podem enriquecer a compreensão do problema de pesquisa. Porém, ambas demandam esforço por parte do pesquisador, para que esse possa dar sentido ao material coletado e analisado.

Com base nestes apontamentos, acredita-se que estar fundamentado e embasado metodologicamente também trará o rigor necessário à pesquisa, aumentando a qualidade e a fidedignidade dos resultados obtidos.

\subsection{Formas de Abordagem}

Neste item, buscou-se identificar como os autores classificaram suas pesquisas quanto ao delineamento da mesma. Para Gil (2002), o delineamento expressa o desenvolvimento da pesquisa e, a partir dos instrumentos de recolha de dados, é possível classificá-la. Segundo o autor, podem ser definidos dois grandes grupos de delineamento: aqueles que usam fontes "de papel" e aqueles que são fornecidos por pessoas. No primeiro, pode-se citar a revisão bibliográfica e a pesquisa documental. Já no segundo, a pesquisa experimental, o estudo de caso, dentre outros.

Nos artigos analisados na QNEsc, assim como em relação às metodologias de pesquisa, a maioria dos autores não classificam suas pesquisas quanto ao delineamento (51\%). A maioria das pesquisas de caráter qualitativo, apenas classificam suas pesquisas como uma "investigação", sem caracterização metodológica quanto a abordagem da mesma. Como já mencionado, apenas classificou-se as dentro das dimensões quando o(s) autor(es) traziam a informação de maneira explícita na metodologia do trabalho.

Dessa forma, entre aqueles que caracterizaram suas pesquisas, o modelo metodológico mais adotado pelos pesquisadores foi o "Estudo de Caso". Uma parte significativa dos trabalhos que não trouxe essas informações poderia ser enquadrada como revisão bibliográfica e/ou análise documental, dependendo do referencial adotado 
pelo pesquisador. Outras abordagens apareceram explicitamente nos trabalhos, porém, com menor frequência se analisadas individualmente, como por exemplo, a pesquisa com história de vida e a investigação-ação.

Na seção temática analisada, as pesquisas caracterizadas como "Estudo de Caso" começaram a surgir com maior frequência a partir do ano de 2011. Apenas um trabalho havia sido caracterizado desta forma antes de 2011, após essa data, 8 artigos foram encontrados. Para Coutinho (2014), esse referencial metodológico é um dos referenciais com maiores potencialidades para o estudo da diversidade de problemáticas que se colocam ao cientista social, o que vai ao encontro com a diversidade das pesquisas publicadas que se apropriaram desse referencial.

Entre os artigos analisados, pode-se citar o trabalho de Silva e Soares (2012), em que os autores analisaram as interações aluno-aluno e professor-aluno e, a partir dessas interações, buscaram compreender como o processo de aprendizagem colaborativa vinculado à interação social, pode atuar como uma ferramenta de suporte para desenvolvimento de um ensino com significado. Os autores justificaram a escolha desse delineamento metodológico a partir da definição de Lüdke e André (2013), afirmando que esse estudo visa à descoberta, retrata a realidade de forma completa e profunda, enfatiza a interpretação em contexto, entre outras características, corroborando com os objetivos centrais do trabalho.

Já no trabalho desenvolvido por Guimarães e Mendonça (2015), com base na metodologia do estudo de caso, utilizaram uma questão sociocientífica a fim de avaliarem as habilidades cognitivas de alunos do ensino médio. O que deve ser ressaltado também desse trabalho, é a aparição do termo validação da pesquisa e dos instrumentos de recolha de dados, uma vez que essa preocupação com a validação ainda não havia sido enfatizada em nenhum outro artigo da revista. E, independente da forma de abordagem metodológica, a preocupação com a validação dos instrumentos é de suma importância pois é um dos aspectos que conferem fidedignidade à pesquisa.

Esses dois exemplos de artigos citados, ilustram a diversidade de problemáticas que esse delineamento metodológico pode abarcar. Segundo Yin (2015), para um estudo de caso é necessário que os investigadores foquem no "caso" para ter uma perspectiva holística do mesmo, contendo uma interpretação completa dos eventos. Isso o difere do “caso de ensino" em que não há necessidade de uma interpretação exata dos eventos e sua finalidade é estabelecer uma estrutura para o debate entre os alunos.

O crescente número de trabalhos na área da educação intitulados como "estudo de 
caso" sem caracterizá-los como tal ou, apenas por considerarem seu desenvolvimento em um grupo reduzido de sujeitos e/ou em apenas uma única unidade (escola, turma), levaram a autora Alves-Mazzotti (2006) a investigar as ideias dos dois autores mais utilizados na área: Robert Stake e Robert Yin. A autora aponta que essas concepções errôneas encontradas nos trabalhos quanto ao estudo de caso, podem ser fruto da própria interpretação inequívoca desse caráter de pesquisa pelas demais literaturas ao julgá-la como uma forma mais fácil de se pesquisar. O que foi percebido, é que a escola/turma escolhida nem sempre é um "caso" de interesse, é apenas um local de coleta de dados, o que faz com que sua interpretação seja superficial e sem contexto. Após a análise das obras, a autora observou que tanto Yin quanto Stake apresentam pontos de convergência e divergência, mas, de um modo geral, ambos reconhecem a importância de se ir além do caso, não de modo quantitativo, mas passível de uma generalização alternativa.

Também para ambos, o estudo de caso é uma investigação qualitativa que deve ser selecionada segundo critérios pré-determinados. Critérios esses que devem estar explícitos na justificativa da seleção, para que esse seja de fato considerado como uma situação complexa, na qual o esforço para sua compreensão seja relevante a ponto de ser classificado como "caso". Além disso, devem ser empregadas várias fontes de dados para que seja possível obter uma visão holística do fenômeno estudado (ALVES-MAZZOTTI, 2006).

O estudo de caso "qualitativo" também apresenta um grande potencial para que se conheça e compreenda os problemas da escola, uma vez que oferece elementos importantes para uma compreensão mais ampla de seu papel e suas relações com outras instituições de nossa sociedade (LÜDKE; ANDRÉ, 2013).

Na pesquisa qualitativa, como estudo de caso ou outro método, é comum a adoção de mais de uma técnica de coleta de dados e, independente da escolha do investigador (observação, entrevista, documentos oficiais, entre outros), todas as informações obtidas a partir destas fontes apresentam um mesmo denominador e a análise de cada um depende exclusivamente das capacidades integradoras e interpretativas do investigador (COUTINHO, 2014). Santos e Greca (2013), reforçam a importância de que em métodos de pesquisas mais gerais, é necessário que se testem outros instrumentos de coleta e análise de dados, ressaltando a necessidade de se ampliar os procedimentos, métodos e instrumentos adotados pelos pesquisadores. 


\subsection{Instrumentos de Recolha de Dados}

Com as leituras das metodologias dos artigos, identificou-se que, a maioria daqueles que não utilizaram do livro didático como instrumento de recolha de dados, adotaram mais de um instrumento em sua pesquisa. A justificativa pode estar de acordo com os tipos de pesquisa realizada, como o Estudo de Caso, em que existem a necessidade de utilizar mais de um instrumento para analisar com profundidade aquele caso. Por isso, no levantamento, foram contabilizadas 136 unidades de significados, categorizados na dimensão de instrumentos de coleta de dados.

Desses 136 instrumentos, o questionário (21) destaca-se como o instrumento mais utilizado entre os pesquisadores, como pode ser observado pelo Gráfico 02. Sendo, esta ferramenta de recolha de dados, em sua grande maioria, acoplada de outro instrumento, como diário de campo, observação, desenhos, entre outros. Seguido dos diários de campo (12) e os livros didáticos (12), e a entrevista (11), sendo esta última apresentando-se como uma técnica de investigação guiada pelo instrumento designado como roteiro de entrevista.

Gráfico 2: Instrumentos e técnicas de Recolha de dados na seção de "Ensino de Química em Foco"

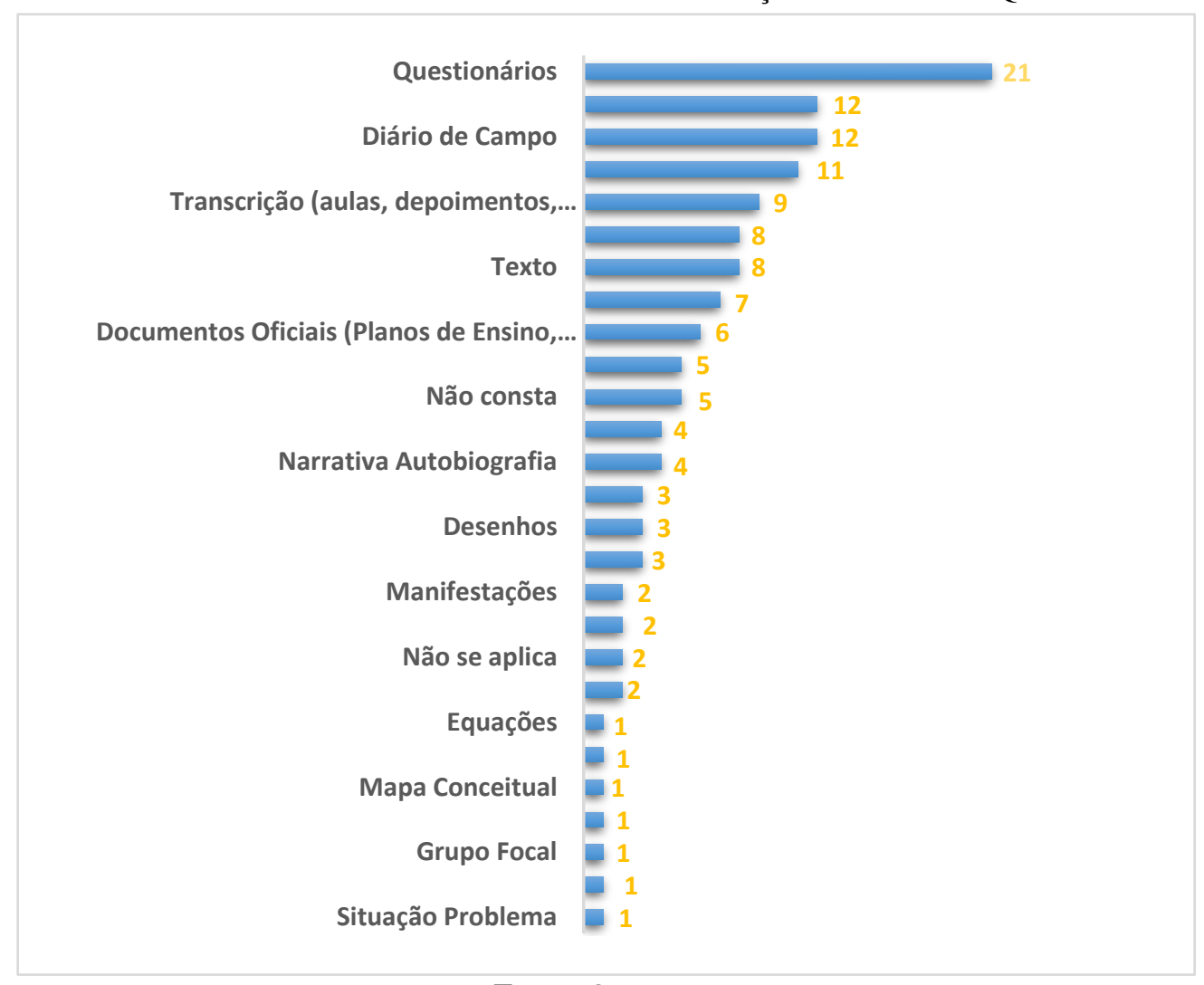

Fonte: Os autores 
Uma tendência observada nesta seção temática a partir do ano de 2008 é a análise de documentos oficiais, como documentos de cursos, planos de ensino, programas oficiais e ementas de disciplinas de cursos de licenciatura.

Nesta categoria, um fator que merece discussão é o de que alguns artigos (5) não descreveram qual foi o instrumento utilizado para recolha de dados. Isto pode estar atrelado ao fato de que alguns artigos não se enquadram na seção temática, uma vez que não eram artigos de pesquisa, mas sim, descrição de relato de experiências ou, até mesmo, proposta de atividades experimentais.

O momento da recolha dos dados é de importância fundamental para a pesquisa. Se esses forem consistentes, farão com que o conhecimento seja construído de forma coerente e significativa. Por isso, é fundamental que o pesquisador se preocupe em promover escolhas condizentes de instrumentos de recolha e procedimentos para a coleta, de forma que esses atendam aos objetivos da pesquisa (MÓL, 2017).

Além disso, ao apontarmos a solidez desses instrumentos, levantam-se as discussões sobre a validade e fidedignidade dos mesmos. Essa preocupação com a validade e fidedignidade não é, ou não deveria ser, exclusividade apenas ao paradigma quantitativo, como apontado por Santos e Greca (2013).

Cada paradigma apresenta suas próprias estratégias de validação dos instrumentos e aumento da credibilidade e fidedignidade dos mesmos. No caso da pesquisa quantitativa, as discussões acerca deste problema são amplas e estão em constante atualização. Já em relação à validade dessas pesquisas, ainda existem críticas quanto aos resultados obtidos nesse paradigma, por isso, é fundamental que os trabalhos contenham argumentações sólidas para que se possa avaliar a utilidade e qualidade dos resultados obtidos (SANTOS; GRECA, 2013).

No paradigma qualitativo, esses pontos parecem ser esquecidos nos trabalhos de pesquisas. Segundo Santos e Greca (2013), o maior problema deste paradigma está nas restrições à fidedignidade, que acabam por afetar a credibilidade da pesquisa. Desta forma, ressaltam mais uma vez a importância das discussões sobre essas questões de maneira explícita nos trabalhos, uma vez que sua ausência enfraquece os resultados das pesquisas.

\subsection{Procedimento de Análise dos Dados}

Uma vez que a pesquisa qualitativa gera uma enorme quantidade de dados 
recolhidos, é preciso que esses sejam organizados e compreendidos. Esse processo, segundo Alves (1991), é contínuo, complexo e não-linear, exigindo um trabalho de redução, organização e interpretação das informações coletadas, que começa já na fase inicial e exploratória, acompanhando toda a investigação. Além disso, a autora aponta que quando dados quantitativos são usados de forma complementar, o tratamento deve ser descrito separadamente.

Ao analisarmos esta dimensão, um fator que desperta a atenção é o de que a maior parte dos artigos (33\%) não apresenta qual foi a metodologia empregada para analisar os dados recolhidos e quais foram os caminhos percorridos de forma sistemática, para chegarem aos resultados obtidos, como apresenta o Gráfico 03. Essa ausência da descrição do procedimento adotado acaba ocasionando uma dificuldade em compreender os percursos metodológicos utilizados pelos pesquisadores.

Outro fator que merece ser apontado é o de que muitos autores adotam categorias para analisar seus dados recolhidos, mas não informam ao leitor "como" ou "de onde" emergiram/chegaram até estas. André (2001) discute as novas perspectivas da pesquisa na área da Educação e de como esta vem sendo questionada quanto à fidedignidade de sua metodologia de pesquisa. Para a autora, o trabalho de pesquisa deve ser devidamente planejado, os dados devem ser coletados após procedimentos rigorosos e a análise deve ser densa e fundamentada; o relatório deve descrever claramente o processo seguido e os resultados alcançados.

Esta falta de informações na descrição da metodologia, também foi um ponto encontrado por Silva e Landim (2014), ao investigarem as tendências de pesquisa no Ensino de Ciências voltadas a alunos com deficiência visual. Nos trabalhos analisados pelos autores em cinco base de dados, os mesmos perceberam que os autores dos trabalhos não deixavam claro nem no resumo, nem ao longo do texto, a abordagem metodológica. 
Gráfico 3: Procedimentos de Análise de Dados

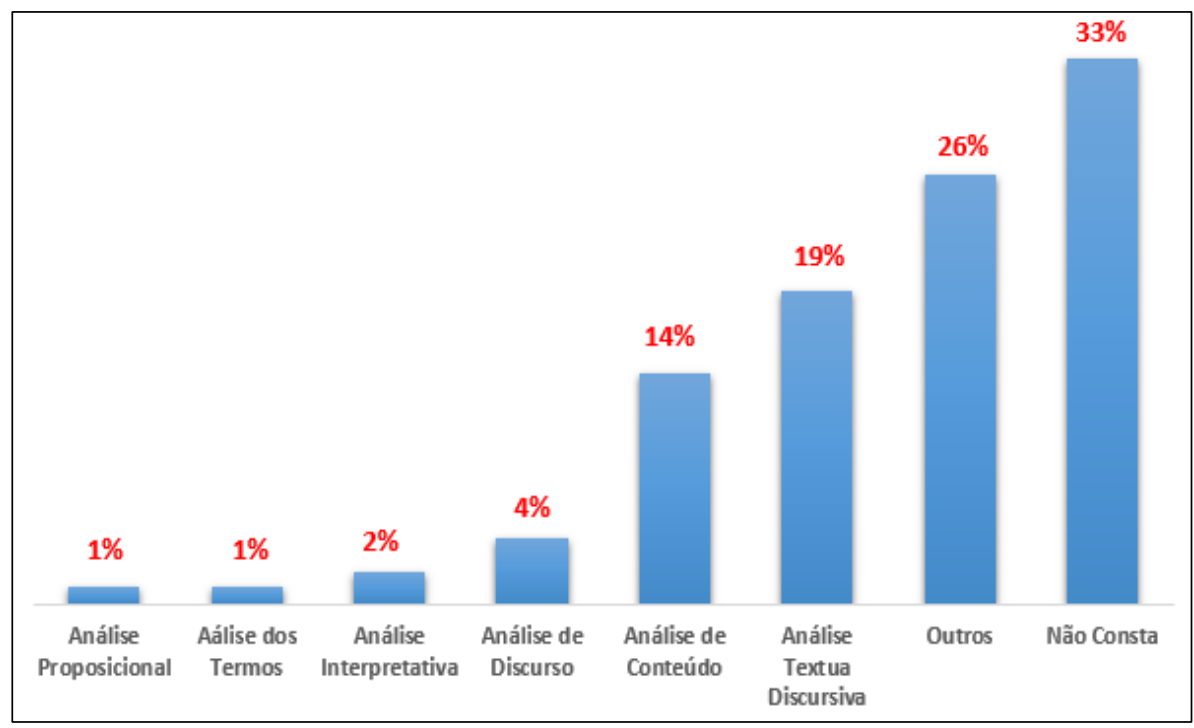

Fonte: Os autores

Dentre as análises mais utilizadas pelos autores está a Análise Textual Discursiva (19\%). Essa análise começa a "ganhar forças" dentro dos trabalhos analisados na revista, a partir do ano de 2007 e, a partir de então, a maioria dos artigos publicados, na seção da revista em questão, se apropria dessa metodologia de análise, deixando em segundo plano a utilização da técnica de análise até então mais utilizada "Análise de Conteúdo" (16\%). Isto nos leva a crer que a Análise Textual discursiva vem sendo uma tendência metodológica de análise na área da Educação Química que vem ganhando espaço e apreço por parte dos pesquisadores.

Outros tipos de análise também foram mencionados em trabalhos, como a “Análise do Relato Verbal”, "Método da História de Vida", "Análise Interpretativa", “Análise do Discurso", dentre outras. Porém, nenhuma dessas análises se destacou em número de artigos publicados como as citadas anteriormente. Ainda, como já era esperado, apenas foram encontrados procedimentos de análise qualitativos, uma vez que as pesquisas com esse paradigma norteador foram encontradas em maior número nos artigos. O único artigo que traz uma análise quantitativa dos dados, caracterizando sua pesquisa como mista, adota uma ferramenta de banco de dados de tabelas.

Com a variedade de instrumentos de recolha de dados, se faz necessário escolher métodos de análises que sejam capazes de transformar e extrair todas as informações colhidas durante o processo de pesquisa e, cada vez mais, discute-se a integração de métodos qualitativos e quantitativos nessa etapa. Para Greca (2002), perde-se muito ao se restringir a apenas uma perspectiva e precisando resgatar perspectivas quantitativas nos estudos em educação, uma vez que os métodos qualitativos e quantitativos estão 
fortemente imbricados e, cada um desses, pode auxiliar no processo de interpretação por mapear aspectos distintos.

Mais importante do que o paradigma em que o investigador enquadra sua pesquisa, é de que esse adote os instrumentos de recolha de dados e opte pelo procedimento de análise mais adequado para interpretar as informações recolhidas e compreender o problema em todas as suas dimensões, para que assim, outros pesquisadores possam utilizar seu trabalho como referência e/ou apropriar-se das informações em seu próprio contexto, contribuindo assim para as mudanças no espaço escolar.

\section{Considerações finais}

Após a análise de todos os artigos, algo que se pode ter claro quanto ao delineamento metodológico das pesquisas no Ensino de Química, dentro da seção "Ensino de Química em Foco" da revista Química Nova na Escola, é de que essa área tem se caracterizado quanto ao caráter qualitativo. Por mais que alguns autores definam suas metodologias como mista, a grande maioria não utilizaram-se de referenciais que dessem esse subsídio as análises quantitativas para seu delineamento e não se apropriaram de metodologias de análise de dados que encaixassem dentro desse paradigma, apenas limitando-se a análise empírica, expressando os dados em porcentagens, sem apropriação de ferramentas que de fato contribuam para esta análise. Alguns pesquisadores podem confundir a caracterização pelo tipo de pesquisa qualitativa e quantitativa, pelo fato de os estudos adotar números para expressar os resultados obtidos, visto que em sua maioria apenas auxiliar na explicitar a dimensão qualitativa.

Entende-se também que uma pesquisa em nossa área de caráter misto possa aumentar a qualidade e o rigor da mesma, uma vez que a apropriação de outras técnicas e metodologia corrobora com a ideia de que as pesquisas na área da educação em ciências percam muito se restringindo apenas a uma única perspectiva, obtendo assim, dados mais sólidos (oriundos da pesquisa quantitativa), profundos e reais (oriundos da pesquisa qualitativa).

Embora o Estudo de Caso tenha sido o tipo de pesquisa mais adotado entre os pesquisadores em nossas análises, percebeu-se um grande número de pesquisas de caráter "Levantamento Bibliográfico". Porém, como os autores não caracterizaram suas pesquisas como tal e nós, em nossa função de investigadoras, partiu-se da premissa de 
não atribuirmos dados que não estivessem explícitos no corpo dos artigos para categorização, não se pode fazer esta atribuição. Caso contrário, essa teria sido a forma de delineamento mais presente nos trabalhos.

Um aspecto que deve ser objeto de reflexão, por se tratar de uma seção em que são divulgados dados de pesquisa, é a falta de dados referentes à análise realizada, uma vez que a maioria não apresentou qual foi a metodologia de análise empregada. E, em alguns casos, os artigos apenas citam qual foi a metodologia, mas não descrevem, tampouco apresentam indicadores do processo de análise, apenas os resultados. Essa falta de informações estende-se a escolha dos instrumentos de coletas de dados, deixando algumas lacunas as formas de recolha de dados para a pesquisa, por não estar explicito os instrumentos, e/ou não estabelecer os objetivos para sua utilização.

A investigação também mostrou que as tendências das pesquisas na área do Ensino de Química publicadas na revista “Química Nova na Escola” no período de 1995 a 2017, estão balizadas pela ausência de um paradigma metodológico que a caracterize. Ainda, por uma forma de abordagem da investigação embasada no delineamento tendo o Estudo de Caso como predominante, em que o questionário como procedimento de recolha de dados é usado na maioria das pesquisas e que não há uma definição precisa quanto aos procedimentos de análise de dados. Portanto, a área de Ensino de Química ainda está em processo de consolidação mostrando que as perspectivas para futuras pesquisas estariam voltadas para a busca de um paradigma qualitativo que pudesse abarcar diferentes formas de abordagem de investigação com maior pluralismo, como também maior diversidade na recolha dos dados para que seja definida e caracterizada os procedimentos de análise.

Sendo assim, acredita-se que mesmo avançando em nossa área quanto às questões metodológicas, ainda existem lacunas que precisam ser preenchidas para que as pesquisas sejam fortalecidas e ganhem cada vez mais espaço significativo no cenário científico, (re)pensando o Ensino de Química, não apenas nas Universidades, mas também, abrindo espaço para os professores da Educação Básica contribuírem nesse processo de mudanças.

\section{Referências}

ALVES, A. J. O planejamento de pesquisas qualitativas em educação. Cadernos de Pesquisa, São Paulo, n. 77, p. 53-61, maio. 1991.

ALVES-MAZZOTTI, A. J. Usos e Abusos dos Estudos de Caso. Cadernos de Pesquisa, São 
Paulo, v. 36, n. 129, p. 637-651, set./dez. 2006.

ANDRÉ, M. Pesquisa em Educação: Buscando Rigor e Qualidade. Cadernos de Pesquisa, [S.I.], n. 113, p. 51-64, jul. 2001.

BENITE, C. R. M.; BENITE, A. M. C.; ECHEVERRÍA, A. R.. A Pesquisa na Formação de Formadores de Professores: Em Foco, a Educação Química. Química Nova na Escola, São Paulo, v. 32, n. 4, p. 257-266, nov. 2010.

BARDIN, L. Análise de conteúdo. 4. ed. Lisboa: Edições 70, 2010.

BOGDAN, R. C.; BIKLEN, S. K. Investigação qualitativa em educação. Tradução Maria João Alvarez, Sara Bahia dos Santos e Telmo Mourinho Baptista. Porto: Porto Editora, 1994.

CAPES. Coordenação de aperfeiçoamento de Pessoa de Nível Superior. Diretoria de Avaliação. Documento de área 2009, Ensino de Ciências e Matemática, 2009.

CAPES. Coordenação de aperfeiçoamento de Pessoa de Nível Superior. Diretoria de Avaliação. Relatório da Avaliação 2013-2016 Quadrienal 2017, Educação, 2017.

CHIZZOTTI, A. A pesquisa qualitativa em ciências humanas e sociais. 12. ed. Petrópolis: Editora Vozes, 2016.

COUTINHO, C. P. Metodologia de Investigação em Ciências Sociais e Humanas: Teoria e Prática. 2. ed. Almedina, 2014.

FERREIRA, C. A. L. Pesquisa Quantitativa e Qualitativa: Perspectiva para o campo da Educação. Revista Mosaico, Rio de Janeiro, v. 8, n. n.2, p. 173-182, jul./dez. 2015.

FLICK, U. Uma Introdução à Pesquisa Qualitativa. 2. ed. Porto Alegre: Bookman, 2004.

FRANCISCO, C. A.; QUEIROZ, S. L. Análise de Dissertações e Teses sobre o Ensino de Química no Brasil: Produção científica de Programas de Pós-graduação em destaque.

Investigações em Ensino de Ciências, Porto Alegre, v. 20, n.3, p. 21-60, 2015.

GATTI, B. A. Estudos quantitativos em educação. Educação e Pesquisa, São Paulo, v. 30, n. 1, p. 11-30, jan./abr. 2004.

GIL, A. C. Como elaborar projetos de Pesquisa. 4. ed. São Paulo: Atlas, 2002.

GRECA, I. M. Discutindo Aspectos Metodológicos da Pesquisa em Ensino de Ciências: Algumas Questões para Reletir. Revista Brasileira de Pesquisa em Educação em Ciências, Belo Horizonte, v. 1, n. 2, p. 73-82, 2002.

GUIMARÃES, D.; MENDONÇA, P. C. C. Avaliação de Habilidades Cognitivas em Um Contexto Sociocientífico com Foco nas Habilidades Argumentativas. Química Nova na Escola, São Paulo, v. 37, n.especial1, p. 35-42, jul. 2015.

LÜDKE, M.; ANDRÉ, M. E. D. A. Pesquisa em educação: abordagens qualitativas. 2. ed. São Paulo: E.P.U, 2013.

MAIA, J. O.; SÁ, L. P.; MASSENA, E. P.; WARTHA, E. J. O Livro Didático de Química nas Concepções de Professores do Ensino Médio da Região Sul da Bahia. Química Nova na Escola, São Paulo, v. 33, n. 2, p. 115-124, maio. 2011. 
MEDEIROS, A. Metodologia da Pesquisa em Educação em Ciências. Revista Brasileira de Pesquisa em Educação em Ciências, Belo Horizonte, v. 2, n. 1, p. 73-82, 2002.

MELO, M.R; NETO, E.G.L. Dificuldades de ensino e aprendizagem nos modelos atômicos em Química. Química Nova na Escola, São Paulo, v.35, n.2, p.112-122, mai. 2013.

MESQUITA, N. A. da S,; SOARES, M. H. F. B. Relações entre concepções epistemológicas e perfil profissional presentes em projetos pedagógicos de cursos de Licenciaturas em Química do Estado de Goiás. Química Nova na Escola, São Paulo, v. 31, n. 2, p. 123-131, maio. 2009.

MÓL, G. D. S. Pesquisa Qualitativa em Ensino de Química. Revista Pesquisa Qualitativa, São Paulo, v. 5, n. 9, p. 495-513, dez. 2017.

MORTIMER, E. F. et al. A pesquisa em Ensino de Química na QNesc: uma análise de 2005 a 2014. Química Nova na Escola, São Paulo, v. 37, n.especial 2, p. 188-192, dez. 2015.

NARDI, R. A pesquisa em ensino de Ciências e Matemática no Brasil. Ciência \& Educação, Bauru, v. 21, n. 2, p.1-5. jun. 2015.

QUADROS, A. L. D. Normas de Submissão. Química Nova na Escola. Disponivel em: http://qnesc.sbq.org.br/pagina.php?idPagina=5. Acesso em: 20 jul. 2017.

SANTOS, F. M. T. D.; GRECA, I. M. Metodologias de pesquisa no ensino de ciências na América Latina: como pesquisamos na década de 2000. Ciência e Educação, Bauru, v. 19, n. 1, p. 15-33, 2013.

SCARPA, D. L.; MARANDINO, M. Pesquisa em Ensino de Ciências: Um estudo sobre as perspectivas metodológicas. In: Encontro Nacional de Pesquisa em Educação em Ciências, 2, 1999, Valinhos, São Paulo. Atas II Enpec...São Paulo: ABRAPEC, 1999, p. 1-15.

SCHNETZLER, R. P. A pesquisa em Ensino de Química no Brasil: Conquistas e Perspectivas. Química Nova, São Paulo, v. 25, n. Supl.1, p. 14-24, maio. 2002.

SCHNETZLER, R. P.; ARAGÃO, R. M. R. Importância, Sentido e Contribuições de Pesquisas para o Ensino de Química. Química Nova na Escola, São Paulo, v. 1, n.1, p. 27-31, maio. 1995.

SILVA, T. S.; LANDIM, M. F. Tendências de pesquisa em Ensino de Ciências voltadas a alunos com deficiência visual. Scientia Plena, Sergipe, v. 10, n. 4, p. 1-12, 2014.

SILVA, V. D. A.; SOARES, M. H. F. B. Conhecimento Prévio, Caráter Histórico e Conceitos: O Ensino de Química a Partir de Uma Abordagem Colaborativa da Aprendizagem. Química Nova na Escola, São Paulo, v. 35, n.3, p. 209-219, ago. 2012.

SOUZA, A. L. V; CAMPOS, M. L.; BENITE, A. M. C. Estudos sobre a Utilização da Comunicação Não Verbal na Aula de Química. Química Nova na Escola, São Paulo, v. 36, n. 2, p. 150-161, maio. 2014.

WARTHA, E. J.; FALJONI-ALÁRIO, A. A contextualização no ensino de Química através do livro didático. Química Nova na Escola, São Paulo, n. 22, p. 42-47, maio. 2005.

YIN, R. K. Estudo de Caso: Planejamento e métodos. 5. ed. Porto Alegre: Bookman, 2015.

Recebido em: 24 de junho de 2018.

Aceito em: 08 de agosto de 2020. 